\title{
Preface: Special Issue on Environmental Toxicology of Trace Metals
}

\author{
Vera I. Slaveykova * (i) and Giulia Cheloni
}

Environmental Biogeochemistry and Ecotoxicology, Department F.-A. Forel for Environmental and Aquatic Sciences, School of Earth and Environmental Sciences, Faculty of Sciences, University of Geneva, Uni Carl Vogt, Bvd Carl-Vogt 66, CH-1211 Geneva 4, Switzerland; giulia.cheloni@unige.ch

* Correspondence: vera.slaveykova@unige.ch; Tel.: +41-22-379-0335

Received: 11 December 2018; Accepted: 12 December 2018; Published: 18 December 2018

check for updates

\section{Introduction}

Trace metals (TMs) have a central role in the functioning of aquatic and terrestrial ecosystems. Both essential and toxic trace metals are involved in different chemical, biological, and physical processes that determine their concentrations, speciation, reactivity, and impact on the biota. Despite the recognized hazards associated with the uncontrolled release of metals in the environment and the measures to reduce their input, metals remain an important threat to terrestrial and aquatic ecosystems. Several metals were included on the list of priority substances of environmental concern, whereas technology-critical elements (TCEs), such as rare-earth elements (REEs) and platinum group metals (PGMs) emerge as contaminants. Important advances were achieved in the past decades with respect to the fundamental understanding of trace metal behavior in the aquatic and terrestrial ecosystems, as well as the role of different modifying factors. On this basis, a key concept such as TMs speciation and bioavailability were developed and revealed the utmost role of the interrelated dynamic biological, chemical, and physical processes in TMs cycling and regulation. Nevertheless, there are some persistent gaps in the knowledge challenging the environmental toxicology of TMs, especially for the conditions that are the most relevant to the natural and impacted environment, such as the presence of multiple stressors and metal mixtures, contaminants of emerging concerns etc.

This Special Issue provides some innovative insights into trace metals in the aquatic and terrestrial environments addressing several of the current gaps in contemporary environmental toxicology.

\section{Highlights}

Understanding the combined action of multiple stressors of a different physical and chemical nature, at varying temporal scales and at different levels of biological complexity, is one of the priorities in the current research agenda of environmental toxicology [1-3]. Cheloni and Slaveykova [4] provided an overview of the literature, and discussed the existing gaps concerning the interactions of TMs and light with photosynthetic microorganisms in the aquatic environment. Literature reviews of more than 100 research papers showed that additive, antagonistic, and synergistic interactions might occur depending on the trace element, light spectrum, exposure sequence, and duration, as well as on the specific sensitivity of the tested microorganisms and the activation of stress responses. Light of different intensities and spectral compositions affected the interactions between trace metals and photosynthetic microorganisms by different direct and indirect mechanisms. In particular, by: (i) Altering the structure and reactivity of dissolved organic matter resulting in a decrease in metal binding capacity and an increase in metal bioavailability (and its effects); (ii) influencing chemical speciation of the redox sensitive metals, such as $\mathrm{Fe}$ and $\mathrm{Cu}$; (iii) enhancing the oxidative activity in the aquatic systems; (iv) influencing trace metal toxicokinetics and toxicodynamics. However, it 
was concluded that further studies under more environmentally relevant light irradiation conditions need to be considered, given that most of the current data originate from studies using UV radiation with intensities much higher than those that could be found in the environment. The authors also pointed out that improving the understanding of the combined action of multiple stressors in complex environmental settings will reduce the uncertainties associated with laboratory-to-field extrapolation of the toxicity data used in environmental risk assessments.

A multi-disciplinary community ecotoxicology approach was employed by Lavoie et al. [5] to assess the health and ecological integrity of Junction Creek and its tributaries in the Sudbury region (Canada), which are under multiple stressors influence due to extended mining activity and increased nutrient load. The responses of diatoms to stressors were observed at the assemblage level, for example the presence and abundance of metal tolerant species and nutrient-loving species, as well as at an individual level, through the presence of abnormal diatom frustules. The cumulative criterion unit approach was used as a proxy for $\mathrm{Al}, \mathrm{Cu}, \mathrm{Cd}, \mathrm{Ni}, \mathrm{Pb}$, and $\mathrm{Zn}$ toxicity to diatom community. The implications of the results in this field study for the development of an ecotoxicology-based assessment of the ecological integrity of aquatic ecosystems and best management practices during mining operation, as well as site rehabilitation after mine closure, were thoroughly discussed.

Improved knowledge of the behavior and toxicity of metal mixtures is required to develop metal-specific concepts and approaches, such as bioavailability and metal speciation, in multiple-metal exposure assessments [6]. The mechanistic study by Guzman-Rangel et al. [7] explored the type and magnitude of the $\mathrm{Zn}$-As toxic interactions on plants grown in soils with different chemical properties sampled from mining sites with $\mathrm{Zn}$-As contamination in Mexico. The results revealed a pronounced antagonism between $\mathrm{Zn}$ and As on barley Hordeum vulgare when relative root elongation was considered as a toxicity endpoint. These antagonistic interactions were more pronounced with concentration addition (CA) models compared with independent action (IA) models. However, no significant interactions (either CA or IA) were found in one soil, characterized by the lowest content of Fe-oxides. The study is one of the few one currently available addressing the toxicity of metal and metalloid mixtures in soil ecotoxicology and taking into account the physicochemical differences in the soil characteristics.

A comprehensive study by Urien et al. [8] focused on the sub-cellular distributions of As, Cd, Cu and Se in the liver and gonads of white suckers, Catostomus commersonii, collected at a reference site and downstream from a mining operation site where fish were exposed to polymetallic mixtures. Liver and gonads were chosen because they are key organs for metabolism and detoxification, and reproduction, respectively. The results demonstrated trace element-specific handling strategies in the heat-stable protein and peptide fraction, with no difference between organs. $\mathrm{Cd}$ and $\mathrm{Cu}$ were found to associate with the heat-stable peptides metallothioneins, whereas Se and As were found to bind to biomolecules of molecular weight below $2 \mathrm{kDa}$. The implications of the results regarding the interpretation of metal binding with heat-stable protein and peptide fractions in future studies of sub-cellular metal partitioning were discussed, as well as the importance of the distinction between "detoxified" or "sensitive" fractions in identifying metals of potential concern in a risk assessment context.

Madenjian et al. [9] explored the interaction between mercury, a contaminant of global concern, and sex in the white sucker population from the Kewaunee River, a tributary to Lake Michigan, and compared it with those found for polychlorinated biphenyls (PCBs). The authors concluded that the whole-fish $\mathrm{Hg}$ concentration of mature white suckers were $97 \%$ methylmercury, as well as these concentrations in males excided those found in females. This observation was suggested to be attributable to males expending energy at a higher rate than females, whereas the differences in habitat use or diet composition between sexes were considered negligible. The contaminant type ( $\mathrm{Hg}$ or PCBs)—sex interaction, was also found to be significant. The implications of the work outcomes to fish consumption advisories on white suckers from Lake Michigan were considered, too.

Xaypanya et al. [10] assessed landfill leachate and sediment qualities in three major landfills that can be found in three countries of the Indochina peninsular region. The specific emphasis of 
the research was on the five, toxic trace elements $\mathrm{As}, \mathrm{Pb}, \mathrm{Cd}, \mathrm{Cr}$ and $\mathrm{Zn}$. Their concentrations and partitioning were linked with the major quality parameters in samples obtained during dry and wet seasons. The total and the dissolved metal concentrations of the leachates were several times higher than the industrial effluent and groundwater standard. However, the metal concentrations were high in sediments and the suspended solids with no significant seasonal variations between dry and wet seasons. Based on the results of the study, the authors suggested an improvement in the management practices. They proposed the use of physical filtration or sedimentation of the suspended solid from the leachate to reduce the metal pollution to the surrounding water and soil. The sediment contamination was considered as of potential future risk of groundwater contamination, especially for the large leachate discharge pond on the Nonthaburi landfill.

Another important issue in environmental toxicology of trace metals concerns the data-poor trace elements such as TCEs. These include PGMs and most of the REEs, which are increasingly used in a large variety of applications, including automobile catalysts and petroleum refining, cell phones, TVs and laptops displays, permanent magnets and rechargeable batteries for hybrid and electric vehicles, numerous medical devices, as well as agriculture and energy technologies. The related activities have significantly altered the biogeochemical cycles of these elements, and consequently, their concentrations in the environment increased together with the concerns about their potential effects on the environment $[11,12]$. The necessity for the assessment of their environmental and toxicological aspects of TCEs, has been recognized as well as the need for the development and optimization of appropriate analytical tools to determining their concentrations and speciation in different environmental compartments [13]. To address this analytical challenge, van der Horst et al. [14] proposed a voltammetric and spectroscopic analyses of PGEs in road dust and roadside soil, collected from roads that lead to a busy traffic light and intersection found outside Stellenbosch in the Western Cape (South Africa). The newly developed bismuth-silver nanoparticles, modified on screen-printed carbon electrode, was successfully applied to the analysis of Pt(II), Pd(II) and Rh(III). Makombe et al. [15] presented a methodology based on the glassy carbon antimony film electrode (GC/SbFE) to quantify trace amounts of REEs Ce, La, and Pr in fresh and surface water samples from an area rich with REEs deposits in Northern Cape Province (South Africa). They compared the obtained results with well-established high-resolution ICP-OES spectrometry for quantification of the REEs. With this showcase, the authors demonstrated that GC/SbFE could be used as a low-cost technique to determine REEs in environmental samples as an alternative, or to complement, the spectroscopy analyses.

Development of novel integrative models is necessary for the improvement of the reliability of predictive exposure assessment [2]. Among the models found at different temporal and spatial scales, those at the river basin scale are of use for management (e.g., in Europe [16,17]). Shrestha et al. [18] tackled this issue by using a multi-model approach integrated in the Open Modeling Interface (OpenMI) platform to model trace metal transport and to predict both dissolved and particulate metal concentrations. To this end, the authors integrated a hydrological model, a soil and water assessment tool, a hydraulic, a storm water management, a stream water temperature; a sediment transport; and a water quality models. The OpenMI was applied to simulate the dynamics of $\mathrm{Cd}, \mathrm{Cu}, \mathrm{Pb}$, and $\mathrm{Zn}$ in Zenne River, Belgium. The performance was evaluated and the projection of the ecological status of Zenne River based on long-term simulation results was proposed. The usefulness of the Open MI platform for integrated modelling of a complex river basin, and environmental management, were further discussed.

Overall, the papers published in this Special Issue of Environments illustrate the large array of ongoing research in the field of environmental toxicology of trace metals that span from aquatic to terrestrial environments, from mechanistic subcellular to more applied basin scale research, from analytical measurements, effect-oriented research with various organisms to modelling and field studies.

Conflicts of Interest: The authors declare no conflicts of interest. 


\section{References}

1. Fischer, B.B.; Pomati, F.; Eggen, R.I.L. The toxicity of chemical pollutants in dynamic natural systems: The challenge of integrating environmental factors and biological complexity. Sci. Total Environ. 2013, 449, 253-259. [CrossRef] [PubMed]

2. Vighi, M.; Villa, S. Ecotoxicology: The challenges for the 21st century. Toxics 2013, 1, 18. [CrossRef]

3. Artigas, J.; Arts, G.; Babut, M.; Caracciolo, A.B.; Charles, S.; Chaumot, A.; Combourieu, B.; Dahllöf, I.; Despréaux, D.; Ferrari, B.; et al. Towards a renewed research agenda in ecotoxicology. Environ. Pollut. 2012, 160, 201-206. [CrossRef] [PubMed]

4. Cheloni, G.; Slaveykova, V. Combined effects of trace metals and light on photosynthetic microorganisms in aquatic environment. Environments 2018, 5, 81. [CrossRef]

5. Lavoie, I.; Morin, S.; Laderriere, V.; Fortin, C. Freshwater diatoms as indicators of combined long-term mining and urban stressors in Junction creek (Ontario, Canada). Environments 2018, 5, 30. [CrossRef]

6. Van Genderen, E.; Adams, W.; Dwyer, R.; Garman, E.; Gorsuch, J. Modeling and interpreting biological effects of mixtures in the environment: Introduction to the metal mixture modeling evaluation project. Environ. Toxicol. Chem. 2015, 34, 721-725. [CrossRef] [PubMed]

7. Guzman-Rangel, G.; Montalvo, D.; Smolders, E. Pronounced antagonism of zinc and arsenate on toxicity to barley root elongation in soil. Environments 2018, 5, 83. [CrossRef]

8. Urien, N.; Jacob, S.; Couture, P.; Campbell, P. Cytosolic distribution of metals (Cd, Cu) and metalloids (As, Se) in livers and gonads of field-collected fish exposed to an environmental contamination gradient: An SEC-ICP-MS analysis. Environments 2018, 5, 102. [CrossRef]

9. Madenjian, C.; Stevens, A.; Stapanian, M.; Krabbenhoft, D.; DeWild, J.; Ogorek, J.; Edwards, W.; Ogilvie, L.; McIntyre, P. Ratio of mercury concentration to PCB concentration varies with sex of white sucker (Catostomus commersonii). Environments 2018, 5, 94. [CrossRef]

10. Xaypanya, P.; Takemura, J.; Chiemchaisri, C.; Seingheng, H.; Tanchuling, M. Characterization of landfill leachates and sediments in major cities of Indochina Peninsular countries-Heavy metal partitioning in municipal solid waste leachate. Environments 2018, 5, 65. [CrossRef]

11. Nuss, P.; Blengini, G.A. Towards better monitoring of technology critical elements in europe: Coupling of natural and anthropogenic cycles. Sci. Total Environ. 2018, 613-614, 569-578. [CrossRef] [PubMed]

12. Ramos, S.J.; Dinali, G.S.; Oliveira, C.; Martins, G.C.; Moreira, C.G.; Siqueira, J.O.; Guilherme, L.R.G. Rare earth elements in the soil environment. Curr. Pollut. Rep. 2016, 2, 28-50. [CrossRef]

13. Cobelo-García, A.; Filella, M.; Croot, P.; Frazzoli, C.; Du Laing, G.; Ospina-Alvarez, N.; Rauch, S.; Salaun, P.; Schäfer, J.; Zimmermann, S. Cost Action TD1407: Network on technology-critical elements (notice)—From environmental processes to human health threats. Environ. Sci. Pollut. Res. 2015, 22, 15188-15194. [CrossRef] [PubMed]

14. Van der Horst, C.; Silwana, B.; Iwuoha, E.; Somerset, V. Spectroscopic and voltammetric analysis of platinum group metals in road dust and roadside soil. Environments 2018, 5, 120. [CrossRef]

15. Makombe, M.; van der Horst, C.; Silwana, B.; Iwuoha, E.; Somerset, V. Voltammetric and spectroscopic determination of rare earth elements in fresh and surface water samples. Environments 2018, 5, 112. [CrossRef]

16. Todo, K.; Sato, K. Directive 2000/60/ec of the European parliament and of the council of 23 October 2000 establishing a framework for community action in the field of water policy. Environ. Res. Q. 2002, 2002, 66-106.

17. European Parliament. Directive 2008/105/EC of the European parliament and of the council of 16 December 2008 on environmental quality standards in the field of water policy, amending and subsequently repealing. Off. J. Eur. Union. L. 2008, 348, 84-97.

18. Shrestha, N.; Punzal, C.; Leta, O.; Bauwens, W. Trace metal modelling of a complex river basin using the suite of models integrated in the OpenMI platform. Environments 2018, 5, 48. [CrossRef]

(C) 2018 by the authors. Licensee MDPI, Basel, Switzerland. This article is an open access article distributed under the terms and conditions of the Creative Commons Attribution (CC BY) license (http:/ / creativecommons.org/licenses/by/4.0/). 